\title{
Students' academic self-concept in mathematics: A path analysis
}

Anajao, Roldan V.

Pintuyan National High School, Philippines (roldan.anajao@deped.gov.ph)

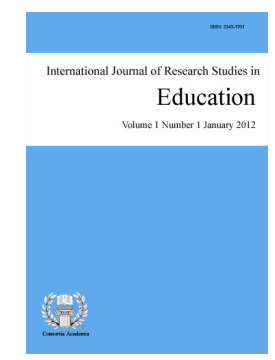

Accepted: 23 August 2021 Online ISSN: 2243-7711

OPEN ACCESS

\section{Abstract}

This study is an attempt to explain how predictor variables - age, sex, mathematics skills, parent's support, availability of learning materials and teacher's attitudes influence students' academic self-concept in mathematics in the Division of Southern Leyte. One school is randomly selected each area among 4 areas in the entire division, where $20 \%$ of each school population is considered the respondents of the study. Correlational Analysis and Regression Analysis are used in determining the direct and indirect predictors. Path Analysis is then used after stablishing the coefficient of each path. The findings of the study reveal that Academic Self-concept is not directly influenced by mathematics skills significantly, however only age and parent's support do. Students' academic self-concept decreases with age but parent support may counter such phenomenon. It can be concluded that parents support plays a vital role in influencing students' academic self-concept especially of students with Low Mathematical skills. Thus, the results are used as the basis for a recommendation for further study in other schools in the Division of Southern Leyte to include variables which are not yet tested and used in this study as predictor variables. It is also recommended that parents' support and teachers attitudes be strengthened more specifically in designing programs or activities to help enhance students' academic self-concept in mathematics.

Keywords: academic self-concept, parents' support, teachers' attitudes, mathematical skills, correlational analysis, regression analysis, path analysis 


\section{Students' academic self-concept in mathematics: A path analysis}

\section{Introduction}

Academic self-concept is referred to as a person's self-evaluation regarding specific academic domains or abilities (Trautwein et al., 2006). It is defined as students' perception of their proficiency (and confidence) in general and/or specific academic areas. In other words, academic self-concept is how students do school work or feel about themselves as learners (Guay, 2003; Harter, 1998). Academic self-concept researches have attracted the interest of researchers in various disciplines because numerous research studies conducted over the past decades have suggested that academic self-concept and academic performance are interrelated. Other studies intended to examine the causal relationships between the two variables (Barker et al., 2005; Helmke \& van Aken, 1995; Marsh et al., 2006). Academic Self-concepts are reciprocally related to academic achievement in the respective domain; that is, achievement predicts self-concept and self-concept in turn predicts subsequent achievement (Chen et al., 2013; Marsh et al., 2006). In this study, the researcher uses academic self-concept as a consequence rather than a cause, and this claims that there are factors that affect students' academic self-concept in Mathematics but these factors influence it in varied ways.

Increasing students' academic self-concept in Mathematics is necessary to equip students the needed critical thinking and skills so as to produce competitive graduates. Undeniably, according to Forbes' analysis in 2014, Philippines continues to power its way as one of the emerging markets that will eventually lead the world in terms of economic growth through developing the critical thinking and skills among our students. It is indeed necessary to strengthen the factors that may affect student's academic self-concept in Mathematics for a well-developed critical thinking skill. Thus, factors affecting students' academic self-concept in Mathematics should be addressed properly to attain such endeavor.

Many factors were observed by many researchers that affect students' academic self-concept in Mathematics. Harter (1989) found that self-concept becomes more differentiated as children develop from infancy to adulthood and suggested that, with development, an increase of self-concept can be articulated as well as differentiated. From this, age manifests with an influence towards academic self-concept. Mathematics is generally termed as a male dominated subject. Campbell (1986) found that girls' lack of confidence in them as Mathematics learners, their perception of mathematics as difficult, and their view that Mathematics is a male activity, all had impact on girls' attitudes and self-concept in Mathematics. In this note, gender matters. But going through this, someone could be a factor as a guiding light to get away from the concept that Math as a subject is gender biased.

One of the considerable factors that may influence students' academic self-concept is the parents. A research finding had shown that a continued effort of parental Involvement throughout the child's education can improve academic achievements and a subsequent better academic self-concept (Driessen et al., 2005; Fan, 2001; Hong \& Ho, 2005). This means that parents' support plays a crucial role in the lives of their children's schooling. However, teachers as "loco parentis" are an extended hand of the parents. As a second parent, school teachers can help and be more effective supporters of students by providing parents suggestions and opportunities for appropriate positive reinforcement. They, likewise should project positive attitudes toward teaching also promotes healthy environment. Moreover, their working attitude promotes self-concept by increasing students' academic skills and perceptions of social support (Elbaum \&Vaughn, 2001). Thus, teacher's positive attitudes and with the use of the learning materials promote self-concept of students in Mathematics, as their materials, facilities and equipment are very important to the learning of the students. Karemera (2003) found that learning facilities like that of library, computer lab and etc. in the institution enhanced students' performance with satisfaction and has significantly contributed to a high academic self-concept. 
The aforementioned concepts pointed out that in the context of Mathematics skills, age, gender, parent's support, teacher's working attitude and availability of learning materials/facilities are predetermined predictor variables that influence students' academic self-concept. Many researches had been done and had found that these predetermined predictor variables had a significant correlation with academic self-concept. However, although various researchers concur with the academic self-concept's correlation with academic achievement, only a few studies have been done to highlight the interconnectedness of these predetermined variables as predictors of students' academic self-concept in Mathematics. The researcher believes that based from these perceived factors, finding the significant correlates of academic self-concept in Mathematics, may it be direct or indirect, could help alleviate the Mathematics performance of the students. Thus, this is the premise on which the conduct of this study is justified.

\subsection{Statement of the problem}

This study aimed to get the significant predictors and of how these factors interact as predictors of academic self-concept among students in the Division of Southern Leyte. Specifically, this sought answers to the following questions:

$>$ What is the profile of the respondents in terms of age, gender (sex), mathematical skills, teacher's attitudes to work, parents' support, availability of learning materials/facilities, and academic self-concept?

$>$ Do the sex, Mathematical skills, teachers' attitudes to work, parents' support and availability of learning materials/facilities directly predict significantly to students' academic self-concept?

$>$ How do the sex, Mathematical skills, teachers' attitudes to work, parents' support and availability of learning materials/facilities influence students' academic self-concept?

\subsection{Significance of the study}

This study would be significant to the following persons. First, to the leaders of Southern Leyte Division, the Schools' Division Superintendent (SDS) and the Education Program Supervisor (EPS) in Mathematics, that they will be aware about the self-concept of Southern Leyte students' in mathematics and plan programs if necessary. Second to the Administrators, Faculty and Staff of all schools within the Division of Southern Leyte, for this study would be of great help as their basis in sustaining and reinforcing the variable that could predict student's academic self-concept in mathematics and to further enhance its achievement in Mathematics. Second, to the Parents, for this will increase their involvement to any school activities and help them track their student's conduct in school. Third, to the Students, for they are the end beneficiary of whatever positive result gained from this study especially on the increase of their Mathematics performance. Lastly, to the Researchers, for this research would really help future researchers as their basis if the line of interest on their study is about correlates of student's academic self-concept in mathematics.

\section{Review of related literature and studies}

Academic self-concept - Academic self-concept refers to mental representations of one's abilities within school or academic settings, or in relation to one's academic progress (Bracken, 2009; Brunner et al., 2010). Manning et al. (2006) posits that it has two levels and it relates to how well one does in school or how well one learns. While the first level deals with the general academic self-concept of how good one is in all subjects; the other has to do with a set of specific content related to self-concept that describes how good one is in Mathematics, Science, Social Studies and English language. Self-concept like any psychological construct is relative and depends on some frame of reference. According to the frame of reference model, academic self-concept will depend on a student's own academic ability and the ability level of other students within the same class. When a student perceives himself as the best in class, he tends to hold a positive self-concept of 
Anajao, R. V.

himself/herself (Acosta, 2007).

According to Morgan et al. and Burns (in Gabriel et al., 2009, p. 107), one's self-concept is an indication of how one feels about himself/herself, and a self-view is important in determining how one learns and behaves. Burns (in Gabriel et al., 2009, p. 107) continues by stating that success or failure in schoolwork or life appears to depend as much on how a person feels about the qualities and attributes he or she possesses as on these qualities themselves. It therefore seems that achievement depends as much on the ability as on the self-concept of the ability of the student. This statement emphasizes the importance of self-concept of ability in an individual. According to Lyon (in McCoach \& Siegle, 2001, p. 71), research suggests that as much as one third of the variance in achievement can be accounted for by academic self-perceptions. This highlights the importance of self-concept in both education and academic achievement.

In support of deeming self-concept as an important educational factor, research has shown that higher levels of self-concept are linked to various educational outcomes, such as academic effort, coursework selections, educational aspirations and 32 academic achievements (Green et al., 2006, p. 534). Self-concept is therefore regarded as an important factor in various areas of education. Dambudzo (2009, p. 7) declares that it is important to investigate the relationship between self-concept and academic achievement in order to rescue those students who may be victims of their own negative beliefs about themselves. This statement is emphasized by Hamachek (1995, p. 419) when he states that academic achievement may not simply be an expression of the students' abilities but also of their perceptions of their abilities, which may help them to feel confident and able, but when negative cause them to feel hesitant and uncertain. In conclusion, it can be deduced from the above that self-concept of abilities is an important variable in education.

Academic self-concept and mathematics skills - Self-concept is frequently positively correlated with academic performance, but it appears to be a consequence rather than a cause of high achievement (Baumeister et al., 2012). This suggests that increasing students' academic skills is a more effective means to boost their self-concept than vice versa. It has also been discovered that academic self-concept has a relationship with academic achievement (Awad, 2007; Tan \& Yates, 2007; Marsh, 2004; Cokley, 2000). Mehta (1968) and Tiwari and Bansal (1984) also showed that high Mathematics skills demonstrates further a high academic self-concept. PISA defines Mathematics self-concept as the extent to which "students' beliefs in their own Mathematics abilities" (OECD, 2013, p. 87).

It is well established in the research literature that Mathematics self-concept and Mathematics achievement are mutually reinforced, since high academic achievement is related to improvements in academic self-concept, but in turn high academic self-concept is also related to improvements in academic achievement (Chen et al., 2013; Guay et al., 2003; Marsh et al., 2002; Marsh et al., 2005; Marsh \& Köller, 2004; Seaton et al., 2014). Independent measures, such as the PISA mathematics tests, have also confirmed the strength of the relationship between mathematics self-concept and Mathematics achievement finding a strong correlation $(r=0.50)$.

Academic self-concept and age - Attempts have been made to consider self-concept changes in the context of life stage analyses. Gordon (1976), for example, uses a "stage-developmental" model based largely on Erikson's (1959) delineation of stage-specific dilemmas to discuss changes in self-concepts over the life cycle. Most research on life-cycle changes in self-concepts has tended to focus on transitions to or from a specific "stage" of development. Rosenberg (1979) found that this disturbance in self-concept is due, not only to biological and hormonal changes, but especially to the shift from elementary school to junior high. Examining students' self-concept through age or by grade level has showed that students in advanced grades had higher self-concepts. Students in the lower grades look up to students in the upper grades for guidance and support. Thus, in this instance, social acceptance promotes an elevated self-concept. Muchera et al. (2010) found that, as students advanced in years and grade levels, their perception of the various aspects of self-concept went up. A possible explanation could be that students improve problem solving skills as they take more mathematics subjects in school (Nelson et al., 2006). 
Academic self-concept and learning materials/facilities - Academic self-concept is influenced by the classroom environment, the learning setting and, most importantly, the instructional processes. The characteristics of the learning context can be studied from a number of different perspectives. While educational psychologists have focused on describing the psychological climate of the learning context, termed the classroom or learning environment (Fraser \& Walberg, 1991), there has also been a focus by educational researchers on aspects of classroom management as an antecedent of the overall classroom climate (Jones \& Jones, 2000). A learning environment can be conceptualized as observable characteristics such as classroom infrastructure, school facilities and externally observed interaction between students and teachers in the classroom (Frenzel et al., 2010). Thus, as part of $21^{\text {st }}$ century skills, it is a necessity to integrate technology in the teaching - learning process. Technology offers enticing possibilities for new approaches to teaching and hence for learning across the curriculum. The research and professional literature suggests that the new approaches may enhance learning through cognitive, metacognitive and affective channels. The cognitive and metacognitive channels for improving learning by using technology are clearly strong and important to study.

Academic self-concept and gender - The 1998 OfSTED Report on 'Recent Research on Gender and Education Performance' stated that one of the subject "science, mathematics, technology, ICT and PE are rated as 'masculine' by pupils and preferred by boys" (Arnot et al., 1998, p. 31). Girls rated English, humanities, music, PSE and RE as feminine and preferred by girls. However, Archer and Macrae (1991) are cited in the same OfSTED report suggesting that mathematics has become more gender neutral perhaps reflected in the smaller gap between genders than that of literacy. The reason of the gap has become smaller may be because girls are more prepared to tackle 'masculine' subjects. In several studies on gender differences in academic self -concept, it has been reported that males and females possess different beliefs about their academic competencies (Ireson et al., 2001; Wigfield et al., 2001; Marsh, 1989), with males showing higher academic self-concept than females (Kling et al., 1999). Different studies have also posited that males tend to have higher academic self-perceptions in science courses while females have higher academic self-perceptions in non-science courses (Harter, 1999; Marsh, 1989).

Academic self-concept and parent's support - Students should be given educational attention from the people that surround him/her. Parents desire that their children climb the ladder of performance to the highest level as much as possible. Parental involvement in a child's education along with environmental and economic factors may affect students' performance. Parents play a crucial role in both home and school environments. Research findings support the existence of a positive relationship between parental involvement and educational success, especially in the secondary years. In general, parental involvement is associated with children's higher achievements in language and mathematics, enrolment in more challenging programs, greater academic persistence, better behavior, better social skills and adaptation to school, better attendance and lower drop-out rates (Henderson \& Mapp, 2002).

Academic self-concept and teacher's working attitude - It has also been suggested that self-concept is not innate but is developed or constructed by the individual through interaction with the sociocultural environment (Shavelson et al., 1976). The development of a supportive classroom environment and the selection of effective learning examples are known to enhance student motivation for learning mathematics (Boyer, 2002). Having their contributions valued was a very significant factor that influenced the way in which students viewed their relationship with mathematics (Anthony \& Walshaw, 2007). Teachers can also help students learn to be more aware of the support they receive (Harter, 1999). Teachers can use appropriate positive feedback to maintain positive self-concept (Manning et al., 2006). Praise, recognition and encouragement are strong determinants of positive self-perceptions. Teachers also can promote academic self-concept by fostering supportive relationships among students. Although the direct effects of teacher working attitude support on student's self-concept remain unstudied, close relationships with teachers' increase students' academic skills (Hamre \& Pianta, 2006) and may indirectly enhance self-concept. This study is anchored from Shavelson's et al. (1976) Self-concept Theory and from the developed theories and models that explain academic self-concept and academic achievement. 


\subsection{Theoretical and conceptual framework of the study}

Shavelson's et al. (1976) theory broadly defines Self-concept as a person's perception of him or herself. These perceptions are formed through one's experience with and interpretation of one's environment, and are influenced especially by reinforcements, evaluations of significant others, and one's attributions for one's behavior. Student's level of proficiency on their mathematical skills is an evaluative feedback and interpretation of his learning in mathematics. Reinforcing student's learning is a requirement to let students understand well the lessons in mathematics. Learning facilities, support of the parents and the attitudes portrayed by the teachers towards teaching could help alleviate the academic self-concept of the students in mathematics.

Self-concept becomes increasingly multi-faceted as the individual develops from infancy to adulthood (Shavelson et al., 1976). Academic self-concept of a person varies with age. Gender stereotypes academic self-concept in mathematics. Many research findings revealed that mathematics is a male dominated discipline. Many researchers have findings that there are factors that affect student's academic self-concept. It is already being given that Mathematics skill is found to be a significant predictor of academic self-concept. Age, Gender, Teacher' working attitude, Parent's support and Learning materials are some which found to be as significant predictors also of student's academic self-concept. Although many researchers have used those mentioned variables as predictors of student's academic self-concept, but only a few have studied how these variables interact with each other in such a way that they can be a direct or indirect predictor of academic self-concept. In this study, this simply means that the six predetermined predictor variables (Age, Gender, Teacher' working attitude, Mathematics skills, Parent's support and Learning materials), shall be tested as direct predictors of Academic self-concept. Afterwards, predictor variables which are not direct significant predictors will be used and tested as indirect significant predictors towards academic self-concept.

\section{Statement of hypothesis}

The predetermined predictor variables - age, gender, Mathematical skills, teachers' attitudes to work, parents' support and availability of learning materials do not significantly influence academic self - concept.

\section{Research design}

This study utilized the Descriptive-correlational design. This design was used to know of what could directly and indirectly predict the academic self-concept of the students in the Division of Southern Leyte. It is descriptive in nature since no intervention or treatments were used to alter the responses of the participants in any way. It is also correlational in the sense that it aims to get the significant relationship of the variables whether predictors or not.

Research respondents and sampling procedure - The respondents of the study were the randomly selected students in Don Agustine F. Escaño National High School (DAFENHS) for IAD I, Libagon National High School for IAD II, Pintuyan National High School for IAD III and Himbangan National High School for IAD IV. These respondents were randomly selected students in the junior high school across all grade levels (Grades 7 10). One (1) school was randomly selected per IAD where $20 \%$ of its population served as respondents. The number of students as respondents per grade level was determined proportionately according to its total population per grade level and were randomly selected. A total of 350 students participated in the study.

\subsection{Research instrument}

Profile of the respondents - The research instrument of this study has four parts. First part is a researcher made tool used for gathering the demographic profile of the respondents comprising of their sex, the number of hours spent by the parents in giving academic advices to their respective student and the availability of learning materials/facilities present in home or school. 
Academic self-concept - The Second part is for obtaining the Student's Academic Self-Concept instrument adopted from the original academic self-concept scale by Liu and Wang (2005) which had to two sub scales; (a) academic confidence, and (b) academic effort, each with 10 items to collect the students' academic self-concept information. The items include both negatively and positively worded items to avoid the same answers from the students. Both academic confidence and academic effort items were mixed in the scale; academic confidence items taking odd numbers $(1,3,5,7,9,11,13,15,17,19)$, while academic effort items taking even numbers $(2$, $4,6,8,10,12,14,16,18,20)$. From the data collected, .795 and .802 were generated for both validity and reliability of the instrument respectively.

Mathematical skills - The third part of the questionnaire was intended to get data on the Students Mathematical Ability. The items in the questionnaire were taken from the Department of Education teacher's guide across all grade levels. Fifteen questions were taken for the first quarter and another 15 questions were taken from the second quarter. A total of 30 questions were set per grade level from grades 7 to10.

Teacher's attitudes - The last part was designed to get the Teacher's working attitude towards teaching Mathematics. This questionnaire was adopted from Analysis of the Attitude Towards Mathematics Inventory (ATMI) of Schackow (2005). This survey contains four attitudinal components: value, enjoyment, self-confidence and motivation. Questions 1-10 related to value, questions 11-20 related to enjoyment, questions 21-30 related to self-confidence and questions 31-40 related to motivation. These teachers' attitudes were categorized into five levels for ease of attitude identification: strongly negative, negative, neutral, positive and strongly positive. These categories were assigned by identifying the possible range of each participant's score by five. ATMI (Schackow, 2005; Tapia \& Marsh, 2002; Tapia, 1996) has shown that measures of internal consistency were high indicating high validity and reliability.

Data gathering procedure - The researcher asked approval from the Program Chair of the Graduate Studies to conduct the study. A letter of permission was further sent to the Division of Southern Leyte addressed to the Schools Division Superintendent and the Education Program Supervisor in Mathematics. Afterwards, a letter to conduct the study was also sent to the respective School Head/Principal of the identified junior high school. The researcher was the one who personally handed-in the questionnaire to the respondents. During the administration of the questionnaire, since more time was asked by the respondents to answer the questions, the researcher asked favor from the identified Math teacher and opted to leave the administered questionnaires with them. The respective Mathematics teacher collected and then contacted the researcher for the questionnaires to be picked up.

Data analysis procedure - Data gathered on the profile of the students in terms of age, sex, teacher's attitudes to work, parent's support and availability of learning material/facilities were analyzed using frequencies and percentages. Correlational Analysis among variables was done to determine which of the predetermined predictor variables have significant relationship towards academic self-concept. Regression Analysis was done to variables which were found to be significantly related to determine the direct predictors of Academic Self-concept. Those variables which are positively correlated in the Correlational Analysis and the other variables which are not direct predictors in the Regression Analysis were used and then regressed as indirect predictors of academic self-concept. After establishing this process, a Path Analysis is formulated through the coefficients of each path of the predictor variables to determine the total effect towards academic self-concept.

\section{Presentation, analysis and interpretation of data}

Table reveals that most students are in appropriate age in their schooling, which means, there is no overage nor underage student among the respondents. This implies that students' academic self-concept is of secondary school age. The result above further reveals that there is not much disparity among boys and girls, and that both sexes are well - represented in terms of their academic self -concept in Mathematics. The result reflected in the table is in consonance with the findings of Matovu (2012) which reveals that academic self-concept of the 
Anajao, R. V.

randomly selected students as respondents in his study are of school - age children and males are with almost equal in number compared to female respondents. Furthermore, Cokely (2000) found that there is also a strong empirical evidence indicating differences in the conceptualization of academic self - concept according to sex and age.

Table 1

Personal profile of the respondents in terms of age and sex

\begin{tabular}{cccccccc}
\hline \multirow{2}{*}{ Age } & \multicolumn{3}{c}{ Male } & \multicolumn{2}{c}{ Female } & & $\%$ \\
\cline { 2 - 5 } & $\mathrm{n}$ & $\%$ & $\mathrm{n}$ & $\%$ & $\mathrm{n}$ & 3.43 \\
12 & 5 & 3.31 & 7 & 3.52 & 12 & 81 & 23.14 \\
14 & 32 & 21.19 & 49 & 24.62 & & 28.29 \\
15 & 45 & 29.80 & 54 & 27.14 & 99 & 21.43 \\
16 & 36 & 23.84 & 39 & 19.60 & 75 & 22.86 \\
17 & 31 & 20.53 & 49 & 24.62 & 80 & 0.86 \\
& & 2 & 1.32 & 1 & 0.50 & 3 & 100.00 \\
\hline
\end{tabular}

Table 2

The profile of the respondents in terms of their math skills

\begin{tabular}{lccc}
\hline \multicolumn{1}{c}{ Math Skills } & $\mathrm{n}$ & $\%$ & Modal Description \\
\hline Did not meet expectations & 294 & 84.0 & \\
Fairly Satisfactory & 6 & 1.7 & Did Not Meet \\
Satisfactory & 14 & 4.0 & Expectations \\
Very Satisfactory & 28 & 8.0 & \\
Outstanding & 8 & 2.3 & \\
\hline Legend: did not meet expectations (below 75), fairly satisfactory (75- 79$)$ satisfactory (80 - 84), very satisfactory (85-89), and outstanding \\
$(90-100)$.
\end{tabular}

Table 2 discloses about majority of the respondents are with grade below the passing grade. This is an indication that the students fall under "Did not meet expectations", which means they are not proficient enough in Mathematics subject. This result simply says that students did not master the needed competencies designed and allotted within the quarter. The result further means that the self-concepts obtained are mostly those of low Mathematical skills. This further implies that students at their level should have focus and double their efforts as possible, for the result speaks in their scholastic performance in Mathematics subject. The result obtained in this study is in line with the findings of Baran et al. (2011) which reveals that high school students mean scores in Mathematics test had the lowest level of computational ability.

\section{Table 3}

The profile of the respondents in terms of their teacher's attitudes

\begin{tabular}{lccc}
\hline \multicolumn{1}{c}{ Teacher's Attitudes } & $\mathrm{n}$ & $\%$ & Modal Description \\
\hline Neutral & 39 & 11.1 & \\
Positive & 39 & 11.1 & Strongly Positive \\
Strongly Positive & 272 & 77.7 & \\
\hline Legend: strongly negative (40-72), negative (73-104), neutral ( & $105-136)$, positive (136-168), and strongly positive (169-200).
\end{tabular}

Table 3 shows that $77.7 \%$ or 272 respondents have teachers manifesting strong positivism towards teaching Mathematics, while $11.10 \%$ is both for positive and neutral teachers. It is then concluded from the result that there is no teacher of the respondents with negative or strongly negative attitude towards teaching Mathematics. This implies that academic self-concept obtained are from students with teachers who have positive attitude towards teaching Mathematics. This result is in consonance of Sweeting's (2011) study, which presents teachers' survey responses pointing only three (3) categories of teacher attitude identified as were strongly positive, positive and neutral. Their result shows that no teacher was identified as having negative or strongly negative results. This connotes that teachers should have enthusiasm in the teaching and should discuss in a manner of algorithm for it leads into an increase of the self-concept of their respective students, for Fennema 
(1996) discloses that many studies suggest that Mathematics instruction should build on students' existing knowledge along with teaching computational algorithms for better self-concept.

\section{Table 4}

The profile of the respondents in terms of parent's support measured through number of hours per week

\begin{tabular}{ccc}
\hline Parent's Support & $\mathrm{n}$ & $\%$ \\
\hline $0-3$ & 288 & 82.29 \\
$4-7$ & 55 & 15.71 \\
$8-11$ & 7 & 2.00 \\
\hline
\end{tabular}

Table 4 reflects the parent's support in terms of the number of hours spent by the parents in giving academic advice. It can be seen that most parents of the students' fall within the range of $0-3$ hours in giving academic advice, for it garnered $82.29 \%$ of the whole sample. This means that parents still find time to get involved in their child's schooling even a minute just to get in touch with them. Fan (2001) demonstrated that parents' educational aspiration for their children proved to be strongly related to students' academic growth. This tells further that the formation of students' self-concept is supported by the parents through spending time in giving academic advice. Research studies have indicated that parental support factors have significant contribution to the development of positive self-concept that is statistically related to academic achievement of the students (Franco \& Levitt, 1998).

\section{Table 5}

The number of availability of learning materials

\begin{tabular}{lccc}
\hline \multicolumn{1}{c}{ No. of Learning Materials } & $\mathrm{n}$ & $\%$ & Modal Description \\
\hline Barely Sufficient & 76 & 21.7 & \\
Moderately Sufficient & 177 & 50.6 & Moderately Sufficient \\
Sufficient & 87 & 24.9 & \\
Very Sufficient & 10 & 2.9 & \\
\hline Legend: Very Sufficient (6-7), Sufficient (4-5), Moderately Sufficient (2-3), and Barely Sufficient (0-1).
\end{tabular}

Table 5 shows the number of availability of learning materials in school. It is evident from the table that 50.6 percent or 177 of the students say that the number of learner's materials available fall between 2-3, while $2.9 \%$ or only 10 among 350 students say that they have very sufficient learner's materials available. Horton (1972) suggested that the ability of individuals in school in their learning instructions was strongly influenced by factors such as the presence of learning materials and facilities. The result implies that the students feel that they are not provided with enough learning materials, where they could explore and discover new learning through interacting towards learning materials and facilities present in school and home. Thus, the availability of learning materials as part of the development of a supportive classroom environment and the selection of effective learning examples are known to enhance student motivation for learning Mathematics (Boyer, 2002).

\section{Table 6}

Profile of the respondents in terms of their academic self-concept

\begin{tabular}{lccc}
\hline \multicolumn{1}{c}{ Academic Self - Concept } & Frequency & Percent & Modal Description \\
\hline Strongly Negative & 1 & .3 & \\
Negative & 33 & 9.4 & Neutral \\
Neutral & 263 & 75.1 & \\
Positive & 52 & 14.9 & \\
Strongly Positive & 1 & .3 & \\
\hline Legend: strongly negative (20-36), negative (37-52), neutral (53-68), positive (69-84), and strongly positive (85-100).
\end{tabular}

Table 7 reveals that students' academic self-concept are neither positive nor negative. This means that their feelings and perceptions in Math are not conclusive on one side. This academic self-concept obtained connotes equilibrium of both sides. This result implies that students given for the fact that they have low Mathematical skills, still has a chance to improve it because their academic self-concept is not relatively low. In recent years, 
Anajao, R. V.

research suggests that positive academic self-concept demonstrates a causal effect on academic achievement (Marsh, 1987). But the academic self-concept of students as reflected does not support a direct proportional relationship towards achievement in Math. The finding of this study is contrary to Marsh et al. (2002) where they reported that academic self-concept and academic achievement influences each other mutually and that an increase in achievement leads to a strong academic self-concept and an increase in academic self-concept causes an important increase in achievement.

Table 7

Correlation matrix of the identified variables

\begin{tabular}{|c|c|c|c|c|c|c|c|}
\hline Variables & & Age & Sex & $\begin{array}{l}\text { No. } \\
\text { Hours }\end{array}$ & LM & $\begin{array}{l}\text { Math } \\
\text { Skills }\end{array}$ & Attitude \\
\hline \multirow[t]{2}{*}{ Sex } & Correlation Coefficient & -0.010 & & & & & \\
\hline & p-value & 0.854 & & & & & \\
\hline \multirow[t]{2}{*}{ No. Hours } & Correlation Coefficient & -0.036 & -0.017 & & & & \\
\hline & $p$-value & 0.498 & 0.753 & & & & \\
\hline \multirow[t]{2}{*}{ LM } & Correlation Coefficient & -0.058 & 0.064 & 0.069 & & & \\
\hline & $p$-value & 0.278 & 0.233 & 0.197 & & & \\
\hline \multirow[t]{2}{*}{ Math Skills } & Correlation Coefficient & -0.276 & 0.082 & -0.144 & 0.075 & & \\
\hline & $p$-value & 0.000 & 0.127 & 0.007 & 0.160 & & \\
\hline Teacher's & Correlation Coefficient & 0.318 & 0.030 & -0.459 & -0.117 & -0.119 & \\
\hline Attitude & $p$-value & 0.000 & 0.570 & 0.000 & 0.029 & 0.026 & \\
\hline Academic & Correlation Coefficient & -0.143 & -0.032 & 0.134 & -0.049 & 0.031 & -0.106 \\
\hline Self-concept & p-value & 0.007 & 0.556 & 0.012 & 0.358 & 0.558 & 0.048 \\
\hline
\end{tabular}

Running for the significant correlation of the predictor variables towards the response variables, results show that Math skills and Parent's support have positive correlation towards academic self-concept. The result also reveals that there are three (3) variables which are found to be significantly related to academic self-concept. These are age, number of hours (parent's support) and teacher's attitude with $p$-value of $0.07,0.012$ and 0.048 respectively. The result reflected in table 7 implies that Math skills have positive relationship towards academic self-concept but not significantly related. Out of three (3) significant predictor variables, only Parent's support which is both positively and significantly related towards academic self-concept. These three (3) identified significant predictors of students' academic self-concept is initial assumptions that have direct effect to the response variable. This assumption leads to the equation

Student's Academic Self-concept = b1 (Age) + b2(No. Hours $)+$ b3(Teacher's attitude) .

After standardizing values, regression coefficients and the corresponding p-values are reflected on the given figure below.

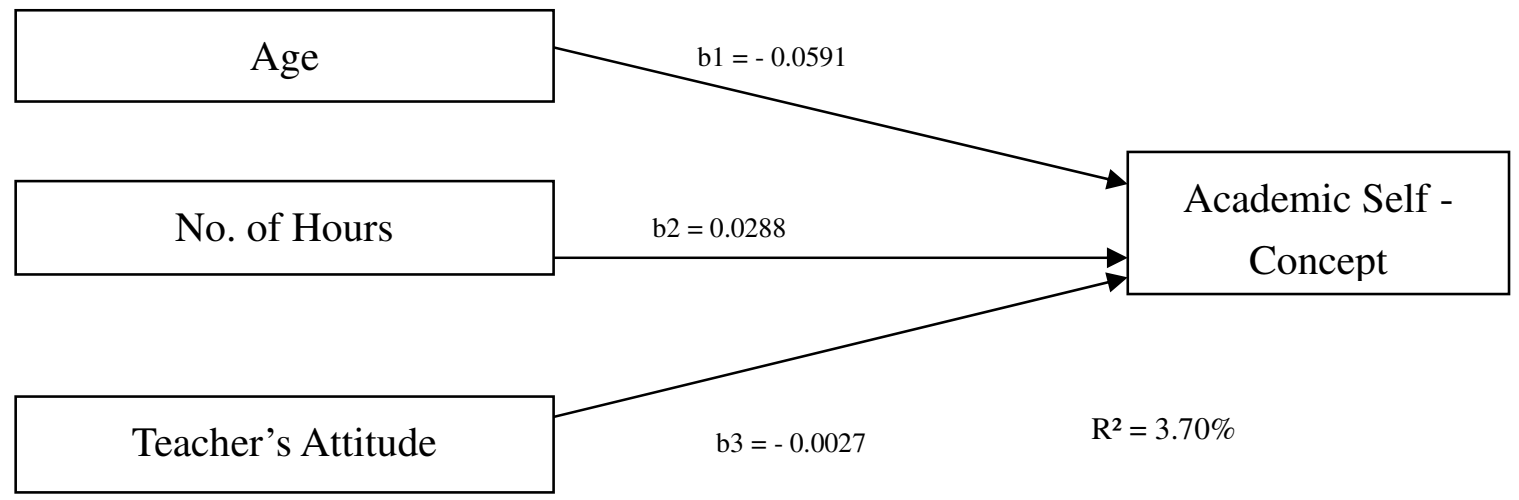

Figure 1. Direct Effects of the Predictors to the Response Variable

The above figure discloses that $3.70 \%$ of the variability of students' academic self - concept may be attributed to the variability in the three predictors. However, it is clear on the above table that teacher's attitude 
has no significant direct influence to students' academic self-concept ( $p$-value $>0.05$ ). The table further says that only Age and Number of hours which significantly predict academic self-concept with $\mathrm{p}$ - value of 0.015 and 0.034 respectively. That is, the two (2) variables are direct predictors and teacher's attitude is just significantly related but not a direct predictor of academic self-concept. This result says that teacher's attitude towards Mathematics does not directly influence academic self-concept significantly. Thus, in the study of Allport (1935) as cited by Sweeting (2011), it was asserted that attitudes as a mental and neutral state of readiness, organized through experience, exerting a directive or dynamic influence upon the individual's response to all objects and situations which it is related.

Another computation is done where teacher's attitude is omitted. The results are reflected in the figure below.

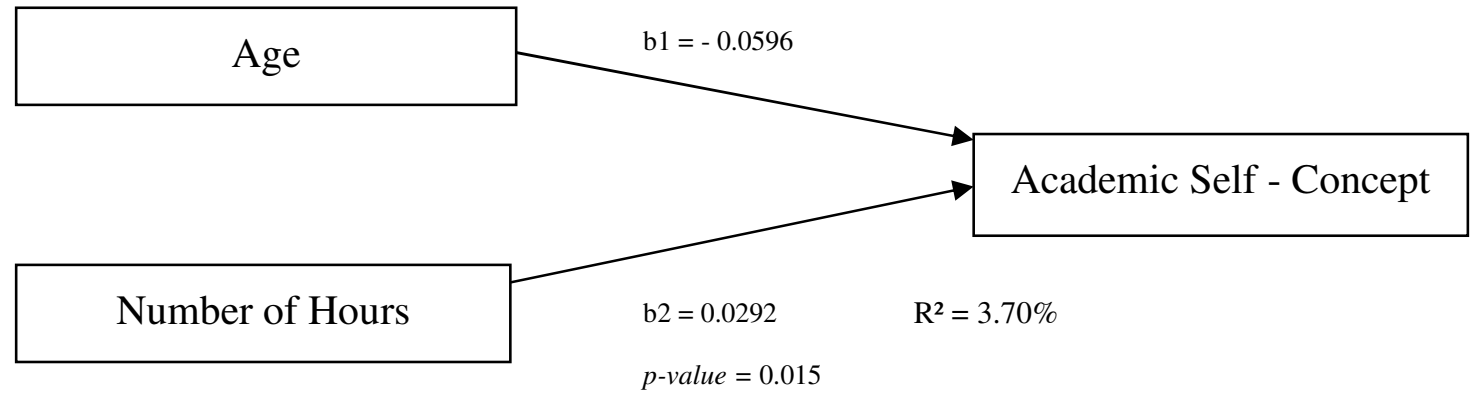

Figure 2. Direct Effects of the Predictors to the Response Variable (revised)

It is evident from the preceding analysis that both age and number of hours have positive significant influence towards academic self-concept. The variability in these two predictors explain $3.70 \%$ of the variability in academic self-concept.

Negative coefficient between age and academic self-concept could mean an inverse relationship to each other. That is, as the age of the person increases, academic self-concept decreases; or the higher the academic self-concept, the younger the person is. This is a clear manifestation that students' academic self-concept changes with age. This result conforms to the previous studies that as the child or student grow, academic self-concept decreases.

Number of hours is directly proportional to academic self-concept which is represented by its positive coefficient. This means that the higher the number of hours spent by the parents in giving academic advice to their students, the better or the higher its academic self-concept in Mathematics. This finding is in consonance with Oselumese et al. (2015) in their assertion that, a child's first educational experiences are centered in the homes; his ideas, attitude and general pattern of behavior are as a result of his childhood rearing. The variation in the academic attainments and self - concept of students could be related directly to differences in the home and its influence. Also, Parental support positively influences children's education. Cohen et al. (2003) stated that children's reading and arithmetic attainment and social adjustments in schools are positively co-related to parental level of education. This is due to that fact that children spend more time at home than they do at schools, and the parents have the opportunity for a number of interactions with their children in one-on-one situations. Thus, parent's support plays vital to the formation of a higher academic self-concept of the students.

Through a positive relationship portrayed in the correlational matrix between Math skills and academic self-concept and with the initial findings of this study, this leads to the hypothetical structure model shown below. 


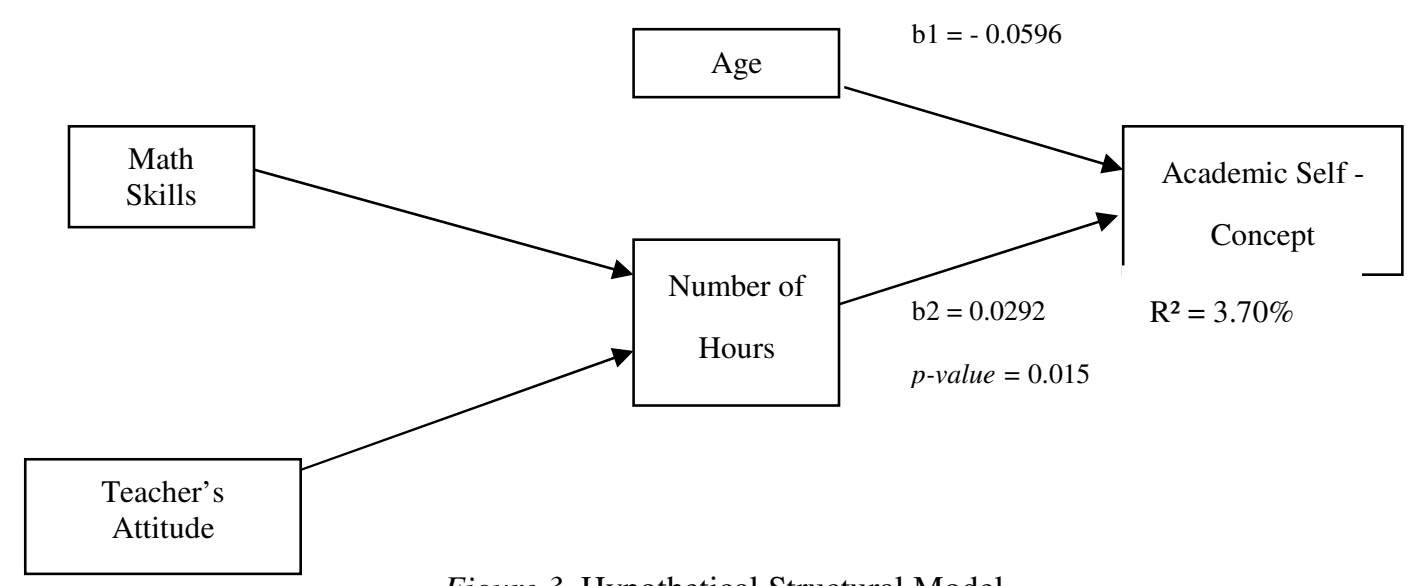

Figure 3. Hypothetical Structural Model

Coefficient for the remaining structural equations; Number of hours = b3(Math Skills) + b4(Teacher's Attitude) are then computed and the final model is obtained below.

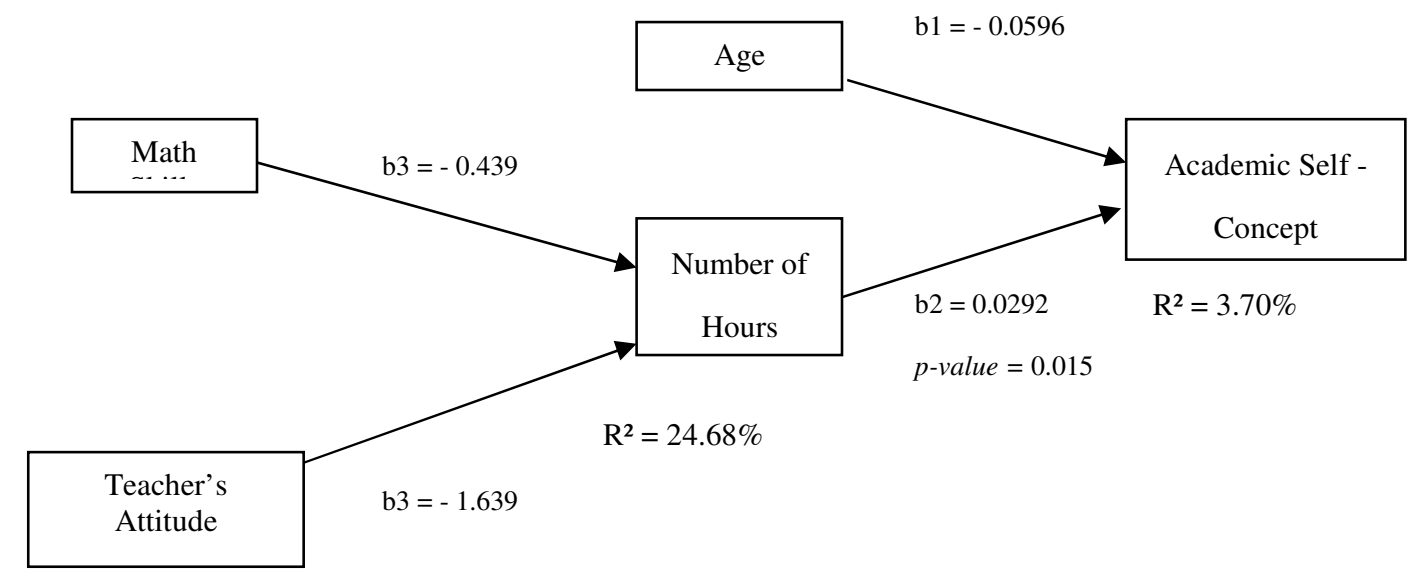

Figure 4. Final Structural Model

It is evident from the final structure model that both Math Skills and Teacher's Attitudes have significant effect towards Number of Hours spent by the parents in giving academic advice to their child. The variability of these two predictors explains $24.68 \%$ of the variability in the Number of Hours.

To sum it all up, the direct, indirect and total effects are then computed and shown in the next table.

\section{Table 7}

Direct, indirect and total effects of the predictors on the academic self-concept

\begin{tabular}{cccc}
\hline Effect & Paths & Coefficient & Total \\
\hline \multirow{2}{*}{ Direct } & Age $\rightarrow$ Self - Concept & -0.0596 & -0.0304 \\
& No. of Hours $\rightarrow$ Self - Concept & 0.0292 & \\
& Math Skills $\rightarrow$ No. of hours $\rightarrow$ Self & $-0.439 * 0.0292=$ & -0.0606776 \\
Indirect & Concept & -0.0128188 & \\
& Teacher's Attitude $\rightarrow$ No. of Hours $\rightarrow$ & $-1.639 * 0.0292=$ & -0.0910776 \\
\hline
\end{tabular}

The analysis reveals that in all, an increase of 1 standard deviation in all predictors shall result to a decrease of 0.0911 standard deviation in academic self-concept. However only Age and Number of Hours spent 
in giving academic advice have direct effects to academic self-concept. A negative direct effect is shown between age and academic self-concept. A positive direct effect is portrayed between Number of Hours and academic self-concept. Age and academic self- concept is inversely proportional implying that as the person gets older it tends to have a lower academic self-concept. While the Number of hours and academic self-concept is directly proportional implying that the more time spent by the parents in giving academic advice, the better or higher academic self-concept the students will have.

On the other hand, Math skills and Teacher's Attitude to work have negative indirect effects towards academic self-concept. This analysis gives us two scenarios. A low academic self-concept is achieved even if a student manifests mathematics skill but with less number of hours is given by the parents in giving academic advice. This result is contrary from the literature of its causal relationship that is a better math skill connotes a higher self-concept or a higher self-concept means a better math skill. This finding could be the result of having moderately sufficient learning materials of students found in their respective homes and schools and with less involvement of their respective parents in their education. Secondly, even with an evident parental support but with a negative teacher's attitude towards teaching mathematics, a decrease in students' academic self-concept still will be indicated. This finding implies that teachers are very influential towards the learning of the students. Therefore, it is a need for every teacher to always look for the best interest of the learners.

The total negative effects of both direct and indirect predictor variables towards academic self-concept signify a bit of a struggle in the parlance of education. But going deeper as to the result reflected in the model, manifesting a total negative effect, it does not mean a total failure of the predictor variables. Hence, the variability of this study speaks only a small portion of the totality. Furthermore, the model explicitly speaks that $96.30 \%$ of contributory predictor variables are not included in this study. However, the predictor variables of this study still have its contributory effect towards the response variables.

Notwithstanding, it is then very necessary to involve parents on the growth of their child's education. It is from then on where their child's academic schooling can be monitored. It further motivates the children to do more as they get older because their parents are there for them. The parents, who wish to educate their children, cannot just rely on school learning, but they need to make some additional arrangements for their children to achieve success, which is vital in influencing students' self-concept.

Teachers also play very vital role in shaping students for a better tomorrow. Teachers should be more caring and they should consider their students' needs and interests and should help them in defining their personal goals. Moreover, they should have the missionary zeal in performing their duties, and they should encourage students in a manner that they perceive themselves as efficient individuals through their own effort and responsibility for the learning process. Thus, in these ways of context, a strong positive academic self-concept especially in Mathematics is not anymore an unreachable star.

\section{Conclusion and findings}

\subsection{Summary of findings}

In the light of the result and analyses of data from the previous chapter, these are the findings.

$>\quad$ Majority of the respondents are females, and ages fall between 14 or 15 .

$>\quad$ The number of hours spent by the parents in giving academic advice ranges from $0-3$.

$>\quad$ The number of learning materials of the students is moderately sufficient.

$>$ Majority of the respondents did not meet expectations in Mathematics skills.

$>\quad$ Teacher's attitudes of the students are strongly positive. 
$>$ Students' academic self-concept in Mathematics is neutral.

$>\quad$ Mathematics skill is positively correlated to academic self-concept but not significantly. Age, Number of hour spent by the parents in giving academic advice and Teachers attitudes are significantly correlated towards academic self-concept.

$>\quad$ Only Age and Number of hours are direct significant predictors of students' academic self-concept in Mathematics. Age possesses negative direct effects and Number of hours shows positive direct effects towards students' academic self-concept.

> Teachers' attitudes and Mathematics skills are indirect significant predictors of students' academic self-concept in Mathematics. These two (2) both possess negative indirect effects towards academic self-concept.

\subsection{Conclusion}

Based on the above findings, it can be concluded that not at all times that Mathematical skills predict academic self-concept, especially among students with low Mathematical skills. Furthermore, this type of students, necessitates significant parental support to boost their academic self - concept.

\subsection{Recommendations}

To increase the Mathematics performance of the school, it is necessary to improve the academic self-concept of students in Mathematics through the following recommendations based on the findings of this study, to wit:

$>\quad 96.30 \%$ of the variability is not explained by the predictor variables used in this study. In this note, it is recommended that a study be conducted to include other probable predictor variables which are not included in this study.

$>\quad$ Teacher should know their students level of academic self-concept. Assessing students' level of academic self-concepts in Mathematics can provide schools with important insights about their students' academic motivation, behaviors, and future becoming.

$>\quad$ Parents should always monitor their students in their schooling through involvement in any school activities. The home environment is the strongest agent in shaping the child's self-concept, so the earlier he is exposed to positive self-concept formation, the better.

\section{References}

Acosta, E. S. (2007). The relationship between school climate academic self-concept and academic achievement. Humanities and Social Sciences, 62(5), 17-27.

Ali, N., et al. (2009). The factors influencing students' performance at Universiti Teknologi MARA Kedah, Malaysia. Management Science and Engineering, 3(4), 81-90.

Allport, G. (1935). Attitudes. In. C. Murchison (Ed.), The handbook of social psychology (Vol. 2, pp. 784-844). Worcester, MA: Clark University Press.

Anthony, C., \& Walshaw, A. (2007). Being a mathematics learner: Four faces of identity. The Mathematics Educator, 17, 7-14.

Archer, B. A., \& Macrae, R. M. (1991). The relationship between a disadvantaged home environment and the self-concept of children: A guidance and counselling perspective. Doctoral Thesis in Psychology of Education, University of South Africa.

Awad, C. (2007). Influence of school organizational culture on public basic school teachers' commitment to the teaching profession. Unpublished master's thesis, University of Cape Coast, Cape Coast.

Barker, K. L., Dowson, M., \& McInerney, D. M. (2005). Effects between motivational goals, academic 
self-concept and academic achievement: What is the causal ordering? Paper presented at the Australian Association for Research in Education (AARE), Sydney, Australia.

Baumeister, R. F., Campbell, J. D., Krueger, J. I., \& Vohs, K. D. (2012). Does high self-esteem cause better performance, interpersonal success, happiness or healthier lifestyles? Psychological Science in the Public Interest, 12, 1-14.

Boivin, M. (2003). The relationship of self-concept and academic achievement. Unpublished master's thesis, Glass Bobo States College, Nigeria.

Booker, A., et al. (2004). Attitude towards mathematics: emotions, expectations and values. Educational Studies in Mathematics, 49, 25-46.

Bracken, B. A. (2009). Positive self-concepts. In R. Gilman, E. S. Huebner, \& M. J. Furlong (Eds.), Handbook of positive psychology in the schools (pp. 89-106). New York, NY: Routledge.

Brunner, M., Keller, U., Dierendonck, C., Reichert, M., Ugen, S., Fischbach, A., \& Martin, R. (2010). The structure of academic self-concepts revisited: The nested Marsh/Shavelson model. Journal of Educational Psychology, 102, 964-981. https://doi.org/10.1037/a0019644

Burns, C. (2007). Examining relationships between academic motivation and personality among college students. Learning and Individual Differences, 20, 19-24.

Byrne, B. M. (1984). The general academic self-concept technological network: A review of construct validation research. Review of Educational Research, 54, 427-456.

Byrne, B. M., \& Shavelson, R. J. (1986). On the structure of adolescent self-concept. Journal of Educational Psychology, 78, 474-481.

Chen, H. Y., Hwang, \& Lin. (2013). Relations of student perceptions of teacher oral feedback with teacher expectancies and student self-concept. The Journal of Experimental Education, 79(4), 452-477.

Choi, N. (2005). Self-efficacy and self-concept as predictors of college students' academic performance. Psychology in the Schools, 42(2), 197-205.

Cohen, W. J., Doyle, W. J., Turner, R., Alper, C. M., \& Skoner, D. P. (2003). Sociability and susceptibility to the common cold. Psychological science, 14(5), 389-395.

Cokley, K. (2000). An investigation of academic self-concept and its relationship to academic achievement in African-American college students. Journal of Black Psychology, 26(2), 148-164.

Dambudzo, I. I. (2009). The relationship between learner self-concept and achievement in secondary schools in Zimbabwe. Unpublished DEd-thesis. Pretoria: Unisa. http://hdl.handle.net/10500/2393

DOST-Science Education Institute. (2014). Expanding our reach, for inclusive growth. Annual Report 2014.

Driessen, G., Smit, F., \& Sleegers, P. (2005). Parental involvement and educational achievement. British Educational Research Journal, 31, 509-532.

Eccles, J. S. (2005). Studying the development of learning and task motivation. Learning and Instruction, 15, 161-171.

Elbaum, B., \& Vaughn, S. (2001). School-based interventions to enhance the self-concept of students with learning disabilities: A Meta-Analysis. Elementary School Journal, 101(3), 303-329.

Erikson, E. H. (1959). Identity and the life cycle. Psychol, 1(1), 171.

Fan, X. (2001). Parental involvement and students' academic achievement: A growth modeling analysis. The Journal of Experimental Education, 70(1), 27-61.

Franco, N., \& Levitt, M. J. (1998). The social ecology of middle childhood: Family support, friendship quality, and self-esteem. Family Relations, 47(4), 315-321.

Fraser, W. (1991). The effects of grouping and curriculum on the self-concept of gifted children. Graduate thesis, submitted to the faculty of the school psychology department college of liberal arts, Rochester Institute of Technology.

Frenzel, A. C., Goetz, T., Pekrun, R., \& Watt, H. M. G. (2010). Development of mathematics interest in adolescence: Influences of gender, family, and school context. Journal of Research on Adolescence, 20(2), 507-537.

Gabriel, A., et al. (2009). Self-concept / academic achievement relations: An investigation of dimensionality, stability, and causality. Canadian Journal of Behavioural Science, 18(2), 173-186. 
Anajao, R. V.

Gordon, C. (1976). Development of evaluated role identities. Ann. Rev. Sociology, 2, 405-433

Green, J., Nelson, G., Martin, A. J., \& Marsh, H. (2006). The causal ordering of self-concept and academic motivation and its effect on academic achievement. International Education Journal, 7(4), 534-546.

Guay, F., Marsh, H. W., \& Boivin, M. (2003). Academic self-concept and academic achievement: Developmental perspectives on their causal ordering. Journal of Educational Psychology, 95, 124-136.

Hamachek, D. (1995). Self-concept and school achievement: Interaction dynamics and a tool for assessing the self-concept component. Journal of Counselling and Development, 73(4), 419-425.

Hamre \& Pianta (2006). Classroom effects on children's achievement trajectories in elementary school. American Educational Research Journal, 45(2), 365-397.

Harlaar, N., Plomin, R., Spinath, B., \& Spinatch, F. (2006). Predicting school achievement from general cognitive ability, self-perceived ability and intrinsic value. Intell., 34, 363-374.

Harter, S. (1986). Processes underlying children's self-concept. In J. Suls (Ed.). Psychological Perspectives en the Self. (Vol. III). Hillsdale, New Jersey: Lawrence Erlbaum Associates.

Hau \& Kong (2002). Explaining paradoxical relations between academic self-concepts and achievements: Cross-cultural generalizability of the internal-external frame of reference predictions across 26 countries. Journal of Educational Psychology, 96, 56-67.

Helmke, A., \& Van Aken, M. A. G. (1995). The causal ordering of academic achievement and self-concept of ability during elementary school: A longitudinal study. Journal of Educational Psychology, 87, 624-637.

Henderson, A. T., \& Mapp, K. L. (2002). A new wave of evidence: The impact of school, family, and community connections on student achievement. Austin, TX: Southwest Educational Development Laboratory. (ERIC Document Reproduction Service No. ED474521)

Hong, S., \& Ho, H. Z. (2005). Direct and indirect longitudinal effects of parental involvement on student achievement: Second-order latent growth modeling across ethnic groups. Journal of Educational Psychology, 97, 32-42.

Horton, C. D. (1972). Humanization of the learning environment. Arlington, VA. (ERIC Document Reproduction Service No. ED066929).

Ireson, J., \& Hallam, S. (2001). Ability grouping in education. London: Chapman.

Jones, F., \& Jones, L. (2000). Comprehensive classroom management: Creating communities of support and solving problems. Needham Heights, MA: Allyn and Bacon.

Karemera, C. (2003). Predictors of scholastic achievement: IQ, self-concept, and time-concept and background characteristics. South African Journal of Education, 19(3), 165-178.

Kling, K. C., Hyde, J. S., Showers, C. J., \& Buswell, B. N. (1999). Gender differences in self-esteem: A meta-analysis. Psychological Bulletin, 125, 470-500

Liu, H. J. (2008). The relationship between EFL student academic self-concept and language performance. Feng Chia Journal of Humanities and Social Sciences, 17, 165-184.

Liu, W. C., Wang, C. K. J., \& Parkins, E. J. (2005). A longitudinal study of students' academic self-concept in a streamed setting: The Singapore context. British Journal of Educational Psychology, 75, 567-586.

Manning, M. A., Bear, G. G., \& Minke, K. M. (2006). Self-concept and self-esteem. In G. G. Bear \& K. M. Minke (Eds.), Children's needs III: Development, prevention, and intervention (pp. 341-356). Washington, DC: National Association of School Psychologists.

Marchargo, J. (1991). The teacher and the self-concept in his or her students. Theory and practice. [El professor y el autocempto de sous alumnus. Teoria y practica]. Madrid: Escuela Espanola.

Marsh, H. W. (1990). Causal ordering of academic self-concept and academic achievement: A multivariate, longitudinal panel analysis. Journal of Educational Psychology, 82, 646-656.

Marsh, H. W., \& Yeung, A. S. (1997). Causal effects of academic self-concept on academic achievement: Structural equation models of longitudinal data. Journal of Educational Psychology, 89, 41-54.

Marsh, H. W., Hau, K., \& Kong, C. (2002). Multilevel causal ordering of academic self-concept and achievement: Influence of language of instruction (English compared with Chinese) for Hong Kong Students. American Educational Research Journal, 39(3), 727-763.

132 Consortia Academia Publishing (A partner of Network of Professional Researchers and Educators) 
Students' academic self-concept in mathematics: A path analysis

Marsh, H., \& Seeshing, A. (1997). Causal effects of academic self-concept on academic achievement: structural equation of longitudinal data. Journal of Educational Psychology, 89(1), 41-54.

Marsh, H., \& Shavelson, R. (1985). Self-concept: Its multifaceted, hierarchical structure. Educational Psychologist, 20(3), 107-123.

McCoach, V., et al. (2001). Intrinsic motivation and determination in human behavior. New York: Plenium.

Mehta, P. H. (1968). The self-concept of the bright under-achieving male high school student'. Indian Educational Review, 3(2), 81-100.

Miujs, D. (1997). Symposium: self-perception and performance. Predictors of academic self-concept: a longitudinal perspective. British Journal of Educational Psychology, 67, 263-277.

Morgan, D. L. (1997). Focus groups as qualitative research. Thousand Oaks, CA: Sage.

Nelson CA, Thomas KM, de Haan M (2006). Neural bases of cognitive development. In W. Damon, R. Lerner, D. Kuhn, \& R. Siegler (Eds.). Handbook of child psychology (Vol. 2, $6^{\text {th }}$ ed). New York: Wiley.

OfSTED (1998). A Report on Recent Research on Gender and Education Performance of students.

Organization for Economic Cooperation and Development [OECD]. (2003). Student engagement at school: A sense of belonging and participation. Paris, France: Author.

Panwar, P. S. (1986). Role of academic achievement and school background in self-concept, self-disclosure and inferiority feeling among students of Kumaun Hills. PhD thesis, Kumaun University, Nainital, India.

Reyes, L. H. (1984). Affective variables and mathematics education. Elementary School Journal, 84(5), $558-581$.

Schackow, J. (2005). Examining attitudes toward mathematics or elementary school teachers enrolled in an introductory mathematics methods course and the experiences that have influenced the development of these attitudes. Unpublished doctoral dissertation. University of South Florida database

Seaton, M., Marsh, H. W., \& Craven, R. G. (2011). The big-fish-little-pond effect under the grill: Tests of its Universality, a Search for Moderators and the Role of Social Comparison', Proceedings of the 5th International Biennial SELF Research Conference 2009: 'Enabling Human Potential: The Centrality of Self and Identity', Dubai, United Arab Emirates.

Shavelson, R. J., \& Bolus, R. (1982). Self-concept: The interplay of theory and method. Journal of Educational Psychology, 74, 3-17.

Shavelson, R. J., Hubner, J. J., \& Stanton, J. C. (1976). Self-concept: Validation of construct interpretations. Review of Educational Research, 46, 407-441.

Strein, W. (1993). Advances in research on academic self-concept: Implications for school psychology. School Psychology Review, 22, 273-284.

Suls, I. M. (1997). Social comparison theory and research: An Overview from 1954. In J. Suls \& R. L. Miller (Eds.), Social comparison processes: Theoretical and empirical perspectives (pp. 1 - 20). Washington, DC. Hemisphere Publishing.

Sweeting, K. (2011). Early years teacher's attitudes towards mathematics.

Tan, J. B. Y., \& Yates, S. M. (2007). A Rasch analysis of the academic self-concept questionnaire. International Education Journal, 8(2), 470-484.

Tiwari, S., \& Bansal, I. (1994). A study of self-concept of high and low achieving adolescent girls. Indian Psychological Review, 43, 21-25.

Trautwein, U., Lüdtke, O., Marsh, H. W., Köller, O., \& Baumert, J. (2006). Tracking, grading, and student motivation: Using group composition and status to predict self-concept and interest in ninth-grade mathematics. Journal of Educational Psychology, 98(4), 788-806.

Wang, J., Liu, L., Wu, H., Yang, X., \& Wang, L. (2014). Agreements between parents and adolescents on emotional and behavioral problems and its associated factors among Chinese school adolescents: A cross-sectional study. BMC Psychiatry, 114-131.

Wigfield, A., Eccles, J. S., \& Rodriguez,D. (2001). The development of children's motivation in school contexts. Review of Research in Education, 23, 73-118. 
Anajao, R. V.

134 Consortia Academia Publishing (A partner of Network of Professional Researchers and Educators) 